ERDC TN-18-1

June 2018

\title{
To Complain or Not to Complain: Spatial Analysis of Complaint Behavior Around Military Installations
}

by Dawn A. Morrison, Edward T. Nykaza, and Nicole M. Wyant

INTRODUCTION: This technical note (TN) explores the spatial patterns associated with the probability of receiving a community complaint in response to blast noise from military training. In this instance, blast noise is defined as high-intensity impulsive noise emitted by large weapons, heavy artillery, and explosions. This TN specifically seeks to understand who in the communities surrounding military installations are more likely to use complaining as a coping strategy. Community noise complaints, which often escalate into lawsuits and legal actions, are an ongoing impediment to military training. They frequently result in training curfews, restrictions, and rangeclosures. The current Department of Defense (DoD) approach to handling noise complaints is ad hoc and reactive, and thus, is generally ineffective. This is a major problem given that noise from testing and training activities impact unit readiness and soldier effectiveness activities. The problem is projected to become worse as installations increase their training capacities and unit throughput as part of the base realignment and closure process (BRAC) (Report to Congress on Sustainable Ranges 2013). Training restrictions due to noise have been cited as one of the factors that will negatively impact installations out to 2025 (Lachman et al. 2011).

Most community noise research has been concentrated on community annoyance in response to noise, both military and otherwise, with not as much effort focused on the use of complaining as a coping strategy for annoyance (Maziul et al. 2005; Guski 1999). That is, not everyone who is annoyed by noise will complain. Complaint behavior is one of several coping strategies available to people annoyed by noise, including habituation, retrofitting of homes, litigation, and relocation away from the noise source (Nykaza et al. 2013; Collette 2011). Research, predominantly focused on community response to airport noise, has identified several demographic and socio-economic variables that are associated with the types of individuals who are most likely to use complaining as a coping strategy in response to being highly annoyed by environmental noise. These variables are age, gender, education level, income level, and housing value. The profile that has emerged is of an older, better educated person with higher income and housing values (Maziul et al. 2005; Nykaza et al. 2013; Collette 2011; Morley and Tomas. 2003; van Wiechen et al. 2002; Dasgupta and Wheeler 1997; Fields 1992; Guski 1977). Some research also indicates that men are more likely to complain about environmental noise, that complainers are likely to be members of environmental organizations, own more than two cars, and live in areas with low population density (Lachman et al. 2011; Nykaza et al. 2013; Dasgupta and Wheeler 1997; Borsky 1979).

There are many possible reasons for why these characteristics are associated with people that complain. Research suggests people complain when the perceived expected benefits received in terms of agency action would be worth the time and effort invested to make the complaint (Fields 1992). It is argued that a person with higher income and education is better able to understand why they should complain, are able to identify and understand how to complain, may feel empowered 
to complain, and may have a sense of entitlement with a willingness-to-pay for better conditions (Nykaza et al. 2013; Fields 1992). Additionally, it has been found that an increased socioeconomic status is correlated to an increased likelihood that residents will use "their verbal and organizational skills to take action against noise" (Morley et al. 2003; Borsky 1979). Hence, it is not that people fitting this profile are more, or less, annoyed by noise than other members of the community, but rather they have the knowledge, skills, wherewithal, and self-empowerment needed to file a noise complaint. The outstanding question this research seeks to address is whether or not this profile - older, educated males with higher income and higher housing values who live in areas with low population density - applies to complaint behavior around military installations in response to training blast noise.

To address this question, a Socio-Economic Complaint Profile Index (the Index) was constructed that composites data for each of the profile categories - age, education, income, housing value, gender and population density. ${ }^{1}$ The Index was then correlated to complaints, to see if a positive relationship existed. Additionally, correlation analysis was used to determine if complaint behavior was associated with a specific Index value or range of Index values.

DATA AND METHODS: Complaint data for this study was obtained from the communities surrounding Aberdeen Proving Ground (APG), located north to northeast of the City of Baltimore on the Chesapeake Bay in Maryland. These communities are located within Cecil, Baltimore, Harford, Kent, Anne Arundel, Queen Anne's, Caroline, and Talbot counties of Maryland. This data was obtained directly from APG from January 2006 to May 2008, for a total of 177 complaints. The complaint records are fairly detailed, including the date the complaint was received, the date and time the noise was heard, and the name and address of complainant. To facilitate analysis of the complaints against the Index, complaints were aggregated to the census tract level and organized into the following categories: total number of complaints $(n=177)$, number of complaints for each year within the study period, $2006(n=71), 2007(n=47)$ and 2008 $(n=59)$, and the total number of complainant households $(n=81)$, which was calculated as a way to remove the potential bias of serial complainers (Collette 2011).

Demographic data was obtained from the U.S. Census Bureau, American Community Survey (ACS) five year estimates for the period covering 2006-2010. The unit of analysis for this research was the census tract level. Data from the following ACS tables were evaluated for potential inclusion in the Index to represent the indicated profile category (Table 1).

\footnotetext{
${ }^{1}$ Due to lack of available data in our study area, membership in environmental organizations and multiple car ownership are not included in the profile.
} 


\section{Table 1. American Community Survey data tables evaluated for potential inclusion in the Socio-Economic Complaint Profile Index.}

\begin{tabular}{|l|l||l|}
\hline \hline \multirow{3}{*}{ Profile Category } & American Community Survey (ACS) Table Name & $\begin{array}{l}\text { ACS Table } \\
\text { Number }\end{array}$ \\
\hline \hline \multirow{3}{*}{ Income } & $\begin{array}{l}\text { Median Household Income in the Past 12 Months (In 2010 Inflation- } \\
\text { Adjusted Dollars) }\end{array}$ & B19013 \\
\cline { 2 - 3 } & $\begin{array}{l}\text { Household Income in the Past 12 Months (In 2010 Inflation-Adjusted } \\
\text { Dollars }\end{array}$ & B19001 \\
\cline { 2 - 3 } & $\begin{array}{l}\text { Per Capita Income in the Past 12 Months (In 2010 Inflation-Adjusted } \\
\text { Dollars) }\end{array}$ & B19301 \\
\hline Age and Gender & Sex by Age & B01001 \\
\hline $\begin{array}{l}\text { Gender and } \\
\text { Education }\end{array}$ & $\begin{array}{l}\text { Sex by Age by Educational Attainment for the Population 18 Years and } \\
\text { Over }\end{array}$ & B15001 \\
\hline \multirow{2}{*}{ House Values } & House Value & B25075 \\
\cline { 2 - 3 } & Median [House] Value (Dollars) & B25077 \\
\hline
\end{tabular}

The first step in constructing the Index was identifying the ACS variables that best represented the individual categories within the profile. Recall that the profile includes an older, better educated male with higher income and higher housing values. The question at hand is, what are the best variables to use to represent each category, and how to define the thresholds for what constitutes "older," "better," and "higher?" For example, is older defined as people aged 40 years and above? 50 years and above? 62 years and above? To address this, several different variables were selected for consideration in each category. The raw data for these variables were converted to location quotients (LQ) (Equation 1), which identified concentrations of people with the individual characteristics relative to both the census tract and the whole study area, normalizing the data for eventual inclusion in the composite Index.

$$
\frac{\left(\frac{\text { Census Tract Variable Population }}{\text { Study Area Variable Population }}\right)}{\left(\frac{\text { Census Tract Population }}{\text { Study Area Population }}\right)}
$$

Once computed, the LQs were evaluated using correlation analysis (Pearson's R) against the complaint data (Figure 1). Because census tracts, as the unit of analysis, have a relatively small geographic scale, and thus, tend to have more variance, a correlation coefficient of at least 0.20 was used as the threshold for determining correlation between the variable and complaints. Individual variables demonstrating the highest correlation coefficients across all of the complaint categories were selected to represent each demographic variable within the profile Index. 


\begin{tabular}{|c|c|c|c|c|c|c|}
\hline \multirow{6}{*}{ Income } & & & $\begin{array}{l}\text { Num_Complaints I } \\
2006\end{array}$ & Num_Complaints I & Num_Complaints & Num_- \\
\hline & & Num Complaints & & & & \\
\hline & Num Households Income $=>\$ 60 \mathrm{~K}$ LQ Total Households & -0.05 & -0.31 & -0.52 & -0.48 & -0.12 \\
\hline & Num Households Income =>\$100K LQ Total Households & -0.05 & -0.37 & -0.50 & -0.22 & -0.14 \\
\hline & Num Households Income $=>\$ 200 \mathrm{~K}$ LQ Total Households & -0.03 & -0.13 & -0.33 & -0.13 & -0.16 \\
\hline & Num People Age $=>62$ LO Total Pop & 0.11 & 0.33 & 0.41 & 0.39 & $0.0 \theta$ \\
\hline \multirow{3}{*}{ Age } & Num Men Age => 62 LQ Total Pop & 0.11 & 0.41 & 0.35 & 0.25 & 0.14 \\
\hline & Num People Age $=>40$ LQ Total Pop & 0.06 & 0.19 & 0.13 & 0.06 & 0.04 \\
\hline & Num Men Age $=>40$ LQ Total Pop & 0.06 & 0.20 & 0.06 & -0.05 & 0.10 \\
\hline \multirow{7}{*}{$\begin{array}{l}\text { Gender \& } \\
\text { Education }\end{array}$} & Num People $\Rightarrow$ Bachelors Degree LQ Total EduSurveyed & -0.04 & -0.09 & -0.39 & -0.15 & -0.25 \\
\hline & Num People => Grad Degree LQ Total EduSurveyed & -0.02 & 0.02 & -0.22 & 0.05 & -0.27 \\
\hline & Num People > High School LQ Total EduSurveyed & 0.00 & -0.16 & -0.23 & -0.09 & -0.25 \\
\hline & Num Men $\Rightarrow>$ Bachelors Degree LQ Total EduSurveyed & -0.05 & -0.14 & -0.36 & -0.13 & -0.29 \\
\hline & Num Men > High School LQ Total EduSurveyed & -0.03 & -0.25 & -0.28 & -0.17 & -0.34 \\
\hline & Num Men $45 \mathrm{Yrs}$ and up $=>$ Bachelors Degree LQ Total EduSurveyed & 0.00 & -0.03 & -0.30 & 0.00 & -0.23 \\
\hline & Num Men 65 Yrs and up $=>$ Bachelors Degree LQ Total EduSurveyed & 0.07 & 0.40 & 0.09 & 0.27 & -0.01 \\
\hline \multirow{4}{*}{ Housing } & Num Housing Values =>\$250k LQ All Houses & 0.02 & -0.12 & -0.21 & 0.20 & -0.18 \\
\hline & Num Housing Values $=>\$ 300 k$ LQ All Houses & 0.01 & -0.05 & -0.13 & 0.23 & -0.15 \\
\hline & Num Housing Values $=>\$ 500 k$ LQ All Houses & -0.03 & 0.12 & -0.18 & -0.09 & -0.11 \\
\hline & Num Housing Values $=>\$ 1$ mil LQ All Houses & 0.03 & 0.52 & 0.40 & 0.23 & 0.14 \\
\hline
\end{tabular}

Figure 1. Pearson's R correlation analysis coefficients, describing the relationship between socioeconomic LQs and complaints. Variables circled with red had the highest correlation coefficients across all complaint types for their profile category.

The second step in constructing the Index was evaluating which combination of variables offered the best and most significant correlation with the complaint data. For this step, thirteen different combinations of variables were evaluated (Table 2), wherein the Index value equaled the sum of the LQs for each individual variable. Each of these combinations were evaluated against the complaint data using correlation analysis (Pearson's R) and the combination with the highest correlation coefficients was selected (Table 3 ).

Based on this analysis, the Index was constructed wherein

Socio-Economic Complaint Profile Index $=\boldsymbol{I} \boldsymbol{i}+\boldsymbol{A i}+\boldsymbol{E} \boldsymbol{i}+\boldsymbol{H} \boldsymbol{i}+\boldsymbol{P D} \boldsymbol{i}$

Where

$$
\begin{aligned}
I_{i} & =\text { Households with Income } \geq \$ 60 \mathrm{k} \mathrm{LQ} \\
A_{i} & =\text { People Aged } \geq 62 \text { Years LQ } \\
E_{i} & =\text { Men } \geq 65 \text { Years with at least a Bachelor's Degree LQ } \\
H_{i} & =\text { Housing Values } \geq \$ 1 \text { million LQ } \\
P D_{i} & =\text { Inverse of Total Population Density LQ }
\end{aligned}
$$

This Index was used to test two hypotheses. The first hypothesis, whether and how significantly the Index correlates with the complaint data, was tested using correlation analysis (Pearson's R) with a significance test based on a t-distribution with $\alpha=0.1$. The significance level was set high because the analysis of the Index is preliminary and exploratory. The second hypothesis, whether or not certain Index values are associated with a higher probability of complaint, was tested using chi-square analysis and conditional probability. Conditional probability, combined with descriptive statistical analysis, determined which Index values, or range of values, had the highest probability of complaint. Chi-square analysis was used to determine whether or not these Index values were in turn associated with complaint behavior, and if so, how significantly. 
Table 2. Socio-economic variable combinations for potential Index inclusion.

\begin{tabular}{|c|c|c|c|c|c|c|c|c|c|c|c|c|c|}
\hline Variable & 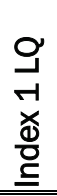 & 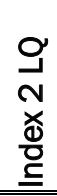 & 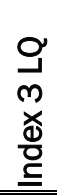 & 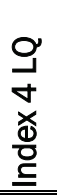 & 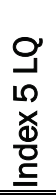 & 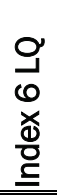 & $\begin{array}{l}\text { 어 } \\
\text { 중 } \\
\text { 으 }\end{array}$ & 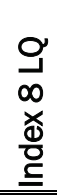 & $\begin{array}{l}\text { 오 } \\
\text { o } \\
\text { త্ } \\
\text { 음 }\end{array}$ & 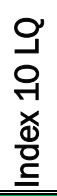 & 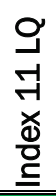 & 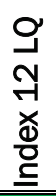 & 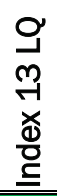 \\
\hline \multicolumn{14}{|c|}{ Inverse Pop Density (People/SqKm) } \\
\hline \multicolumn{14}{|l|}{ Median House value $(\$)$} \\
\hline \multicolumn{14}{|l|}{$\begin{array}{l}\text { Per capita income in the past } 12 \\
\text { months ( } 2010 \text { inflation-adj\$) }\end{array}$} \\
\hline \multicolumn{14}{|c|}{ Num Households Income $=>\$ 60 \mathrm{~K}$} \\
\hline \multicolumn{14}{|c|}{ Num Households Income $=>\$ 100 \mathrm{~K}$} \\
\hline \multicolumn{14}{|l|}{ Num People Age => 62} \\
\hline \multicolumn{14}{|l|}{ Num Men Age $=>40$} \\
\hline \multicolumn{14}{|l|}{ Num People > High School } \\
\hline \multicolumn{14}{|l|}{ Num Men => Bachelors Degree } \\
\hline \multicolumn{14}{|l|}{$\begin{array}{l}\text { Num Men 45Yrs and up } \\
=>\text { Bachelors Degree }\end{array}$} \\
\hline \multicolumn{14}{|l|}{$\begin{array}{l}\text { Num Men 65Yrs and up } \\
=>\text { Bachelors Degree }\end{array}$} \\
\hline \multicolumn{14}{|l|}{ Num Housing Values $=>\$ 250 \mathrm{k}$} \\
\hline \multicolumn{14}{|l|}{ Num Housing Values $=>\$ 500 \mathrm{k}$} \\
\hline Num Housing Values $=>\$ 1 \mathrm{mil}$ & & & & & & & & & & & & & \\
\hline
\end{tabular}

Table 3. Correlation coefficients for top four variable combinations.

\begin{tabular}{|c|c|c|c|c|c|}
\hline \multicolumn{6}{|c|}{ Pearson's r } \\
\hline & $\begin{array}{c}\text { Num_- } \\
\text { Complaints }\end{array}$ & $\begin{array}{c}\text { Num_Complaints } \\
\text { 2006 }\end{array}$ & $\begin{array}{c}\text { Num_Complaints } \\
\text { 2007 }\end{array}$ & $\begin{array}{c}\text { Num_Complaints } \\
\text { 2008 }\end{array}$ & ${ }_{\text {CompHouseholds }}^{\text {Num_ }}$ \\
\hline Index 11LQ & 0.130 & 0.517 & 0.460 & 0.233 & 0.158 \\
\hline Index12LQ & 0.115 & 0.345 & 0.269 & 0.149 & 0.095 \\
\hline Index1LQ & 0.053 & 0.531 & 0.286 & 0.279 & 0.066 \\
\hline Index13LQ & 0.122 & 0.417 & 0.294 & 0.174 & 0.115 \\
\hline
\end{tabular}

RESULTS: The Index produced a value for each census tract in the study area, with values ranging from 0-58. The results of Pearson's R correlation analysis of the Index against complaints indicate a positive relationship between the Index and each of the complaint variables (Figure 2). The strongest relationship between the Index and complaint behavior occurs when the complaint variables are broken out by year. Additionally, even though the correlation coefficients are low, they can still be interpreted to indicate a fairly strong positive relationship, particularly for the 2006 and 2007 complaint variables, given that the unit of analysis, the census tract, is such a small area. 


\begin{tabular}{|c|c|c|c|c|c|}
\hline \multirow{6}{*}{$\begin{array}{l}\text { Hypotheses: one-sided } \\
\qquad \mathbf{H}_{0}: \mathbf{r} \leq \mathbf{0} \\
\mathbf{H}_{\mathrm{a}}: \mathbf{r}>\mathbf{0} \\
\text { Significance Level: } \alpha=.10 \\
\text { Test Statistic: } t \text { distribution }(\mathrm{df}=257) \\
\text { if }|\mathrm{t}|>1.7 \text {, then reject } \mathrm{H}_{0}\end{array}$} & Index11LQ & Pearson's r & $p$-value & $t$ distribution & $H_{0}$ Decision \\
\hline & Num_Complaints & 0.130 & 0.0365 & 2.10 & Reject \\
\hline & Num_Complaints_2006 & 0.517 & 0.00001 & 9.69 & Reject \\
\hline & Num_Complaints_2007 & 0.460 & 0.00001 & 8.31 & Reject \\
\hline & Num_Complaints_2008 & 0.233 & 0.000154 & 3.85 & Reject \\
\hline & Num_CompHouseholds & 0.158 & 0.010881 & 2.57 & Reject \\
\hline
\end{tabular}

Figure 2. Pearson's R correlation analysis for the Index and noise complaints.

All of the test statistics (Figure 2) were significant for a one-sided hypothesis test, which means that the null hypothesis that the Index is not correlated to complaints $\left(\mathrm{H} 1_{0}: \rho \leq 0\right)$ can be rejected for all of the complaint variables. Although the actual correlation coefficients are low, the relatively small complaint sample size of $n=259$, allows for higher confidence in the correlation tests. This indicates that not only is the Index positively correlated with complaint behavior around APG for the study period, but the correlation is statistically significant.

While complaints are significantly correlated to the Index, a map of census track Index scores does not show enough differentiation to be worthwhile for identifying which communities are more or less likely to use complaining as a coping strategy (Figure 3). The census tracts with the highest Index values (shaded red) fall to the far south of the study area where there were no complaints registered during the study period. This indicates that correlation between Index values and complaint behavior alone is not enough to identify who among the population is most likely to engage in complaint behavior in response to military blast noise. However, a range of Index values, combined with previous census tract complaint history, may be able to predict complaining as a coping mechanism.

Of the 124 census tracts surrounding APG, only 34 filed a noise complaint between 2006 and 2008. Of these $34,74 \%$ of all complaints occurred within census tracts with Index values ranging from $35-42$ (Figure 4). A total of $48 \%$ of census tracts fall within this Index range. Given that a census track has an Index value between 35 and 42, the probability that the census tract will lodge a complaint can be determined using conditional probability

$$
P(\text { Complaint } \mid \text { IndexValue }=[35,42])=\frac{P(\text { Complaint } \bigcap \text { IndexValue }=[35,42])}{P(\text { IndexValue }=[35,42])}=\frac{25 / 124}{0.48} \approx 0.42
$$

While a conditional probability of $42 \%$ is lower than desired, chi-square analysis confirms that complaint behavior is strongly associated with an Index value between 35 and 42. To enable chisquare analysis, the data was categorized into binary categories of Complaint $(\mathrm{Y} / \mathrm{N})$ and Index Value 35-42 (Y/N). The Y Complaint and Index Value categories had frequencies higher than five, meeting the minimum assumptions for chi-square analysis. The chi-square statistic and its associated $p$-value of 0.0013 indicates the second null hypothesis that complaint behavior is independent of Index value of the highest probability can be confidently rejected and the alternative hypothesis that complaint behavior is associated with the Index value of the highest probability can be accepted. 


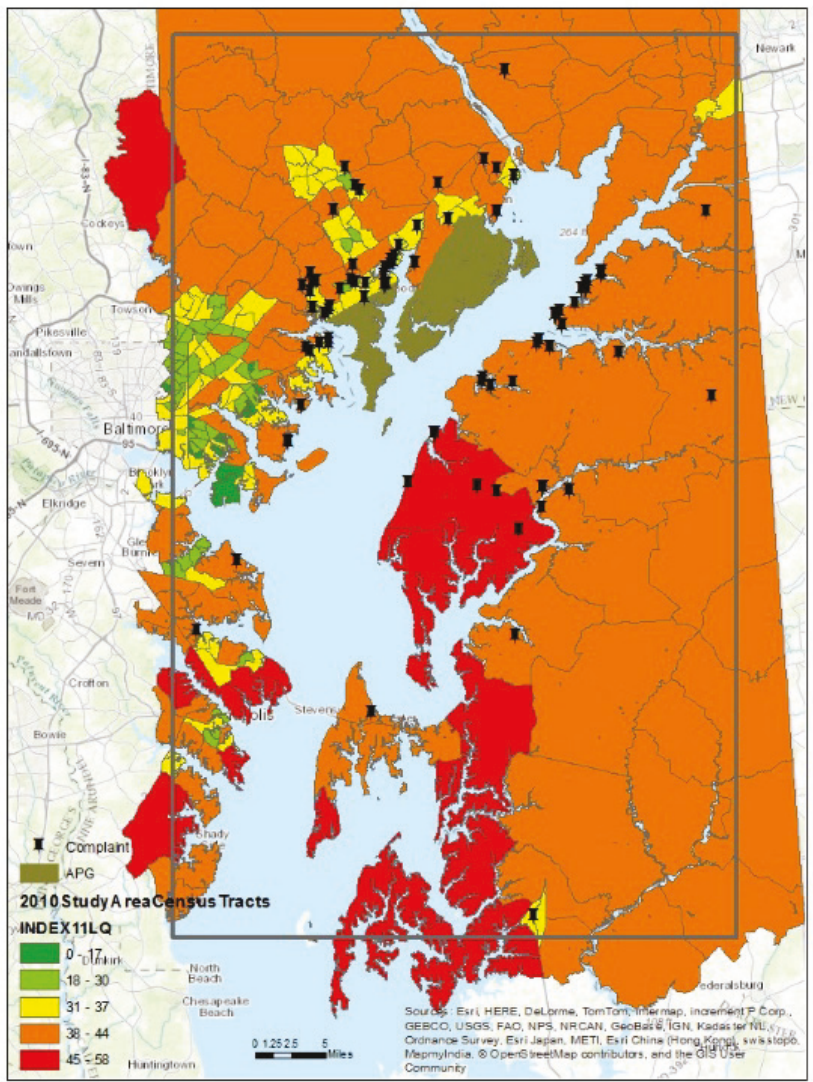

Figure 3. Map of census tracts surrounding APG, the census tract Index values, and locations of filed noise complaints.

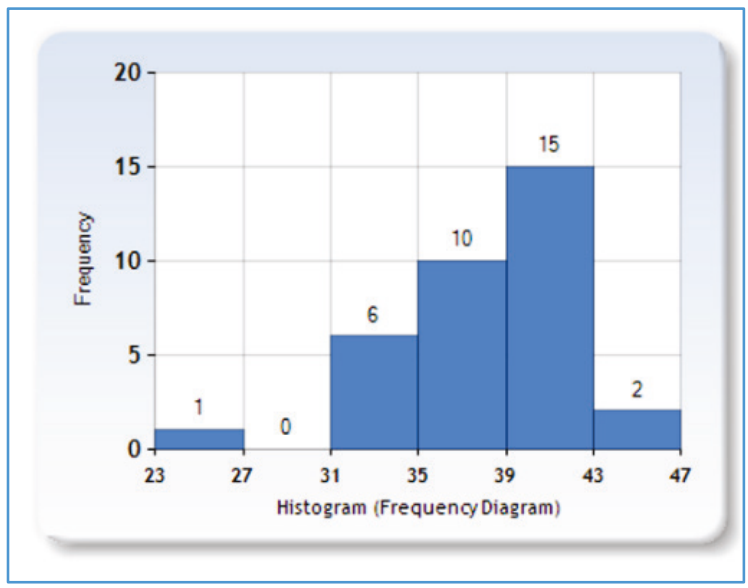

Figure 4. Histogram of Index values for census tracts containing a complaint. The $x$-axis represents the range of Index values and the $y$-axis represents the number of census tracts with Index values within the range. 
SUMMARY: This research set out to examine who, or what subset of the population, are more likely to use complaint behavior as a coping strategy in response to military training blast noise, and whether or not a clear spatial pattern could be identified through the application of the Index. Results indicated that there is promise to the Index and its ability to identify sub-group communities surrounding military installations that are most likely to use complaining as a coping strategy. The Index itself is significantly correlated with the complaint data. Additionally, the spatial pattern of census tracts having an Index value between 35 and 42 are strongly associated with census tracts having a complaint. As a whole, this provides support for the overarching hypothesis that people who are more likely to use complaining as a coping strategy for annoyance caused by military training blast noise fit the profile of an older, educated male with higher income values, higher housing values, and living in an area with low population density.

However, as indicated by the map in Figure 3 and by the conditional probability of having a complaint given an Index value between 35 and 42 of only $42 \%$, the Index requires further development. To this end, there are two main refinements to be considered. The first involves refining the scale of analysis down to the census block level and reevaluating the variables used in the Index. This has the potential to better pinpoint the sub-groups that fit the profile by reducing the area of consideration, resulting in a more focused and differentiated map.

The second area of refinement involves adding a noise impact weight to the Index. Military installations, in accordance with environmental impact regulations, produce noise impact maps that identify the areas around the installation that are at both moderate and high risk for complaints under neutral and unfavorable weather conditions. Adding a variable to the Index to account for the areas that fall within each of these categories would provide further differentiation in the results. Currently, no distance or noise impact variable is considered which allows census tracts that are located in places where the noise is rarely, if ever, likely to reach to be considered equally with those areas that the noise often and frequently reaches.

Additional refinements also include casting a wider net on the variable selection process. Enabling the operating hypothesis was the presumption that military training blast noise is similar to airport and other environmental noise (ergo, presuming that all environmental noise is the same in terms of ability to generate annoyance and complaints), and therefore, the profile that emerged from research into the other environmental noise issues would transfer and apply to military training noise. However, further investigation is warranted to see whether or not there are other profile elements that may be unique to people who use complaining as a coping strategy in response to military blast noise.

Similarly, future research will break the analysis out by year rather than the current method which aggregates the complaints and data across the entire study period. The correlation analysis involved in constructing and evaluating the Index, which was conducted over all of the complaint categories, indicates that stronger correlation coefficients occur when complaints are broken out by year. Future research will use the American Community Survey one year estimates at the census block level, and run the analysis separately for each year within the study period.

It is anticipated that refining the analysis as described above will improve the ability of the Index to be used to forecast which sub-groups and communities have the highest probability for using complaining as a coping strategy in response to military blast noise, and that the conditional 
probability of receiving a complaint given a certain Index value will improve from the current $42 \%$. If this improvement is achieved, the next steps for the research will be to obtain complaint datasets from other military installations and test whether or not the method and Index are useful in forecasting complaint activity. This information will provide justification for whether or not this method is useful for understanding complaint behavior around all military installations, or if it only applies to the communities around APG. Ultimately, the end goal, if the method and SocioEconomic Complaint Profile Index prove viable at multiple military installations, is to incorporate the method into a holistic Community Response Forecasting System to help better mitigate the impacts of military training noise.

\section{REFERENCES}

Borsky, P.N. 1979. "Sociopsychologicla factors affecting the human response to noise exposure." Otolaryngologic Clinics of North America 12(3): 521-535.

Collette, Jonathan D. 2011. "Self-reported aircraft noise complaints and socioeconomic demographics in the greater Philadelphia region: A survey of complaint data from 1997 to 2009." Journal of Aviation Technology and Engineering 1(1): 42-54.

Dasgupta, Susmita and David Wheeler. 1997. "Citizen complaints as environmental indicators: Evidence from China." Policy Research Working Paper 1704. The World Bank: Policy Research Department, Environment, Infrastructure, and Agriculture Division.

Fields, James M. 1992. Effect of personal and situational variables on noise annoyance: With special reference to implications for en route noise. Final Report. Washington, DC: Office of Environment and Energy (DOT/FAA/EE-92-03).

Guski, Rainer. 1977. "An analysis of spontaneous noise complaints." Environmental Research 13: 229-236. https://doi.org/10.1016/0013-9351(77)90099-8.

Guski Rainer. 1999. "Personal and social variables as co-determinants of noise annoyance." Noise \& Health 1(3):4556.

Lachman, Beth E., Agnes Schaefer, Nidhi Kalra, Scott Hassell, Kim Curry Hall, Aimee E. Curtright, David E. Mosher. 2011. Key Trends that Will Shape Army Installations of Tomorrow. Santa Monica, CA: RAND Corporation.

Maziul M., R. F. S. Job, and J. Vogt J. 2005. "Complaint data as an Index of annoyance-theoretical and methodological issues." Noise \& Health 7(28):17-27.

Morley, H., K. Hume, and C. Thomas. 2003. "Socio-economic status of aircraft noise complainers." In Proceedings of the 8th International Congress on Noise as a Public Health Problem, Rotterdam, The Netherlands 274-275.

Morrison, Dawn. A., Jose Gonzalez, and Edward T. Nykaza. 2016. Probability of receiving a blast noise complaint based on population density. The Journal of the Acoustical Society of America 140:3095.

Nykaza, Edward T., Kathleen K. Hodgdon, Trent Gaugler, Peg Krecker, and George A. Luz. 2013. "On the relationship between blast noise complaints and community annoyance." The Journal of the Acoustical Society of America 133:2690-2698.

van Wiechen C. M. A. G., E. A. M. Franssen, R. G. de Jong, E. Lebret. 2002. "Aircraft noise exposure from Schiphol airport: A relation with complainants." Noise and Health 5(17):23-34.

NOTE: The contents of this technical note are not to be used for advertising, publication, or promotional purposes. Citation of trade names does not constitute an official endorsement or approval of the use of such products. 